\title{
On Semantic Patterns of Kill-Verbs in Modern English
}

\author{
Robert Khachatryan \\ Yerevan State Linguistic University
}

\begin{abstract}
The objective of this article is to reveal the semantic patterns of lexical causatives
1 in Modern English, particularly elaborating on the expression of the nuclear meaning to cause to die and the main features of kill-verbs. More specifically, this article reveals semantic characteristics that contemplate on the causativity of lexical causatives (also known as covert or underived causatives), namely based on a new approach to the already existing classifications of kill-verbs (Khachatryan 2012). Within the confines of this article, only kill-verbs with the nuclear meaning to cause to die with most frequent occurrences in speech, namely to kill, to murder, to assassinate, to execute, and to massacre are studied. Linguistic data for the analysis of kill-verbs are mainly taken from the British National Corpus (BNC). Linguistic data from the BNC may entail discern patterns of usage that are not apparent in the examples from fiction. Moreover, as words can acquire a broader meaning and usage in fiction, especially when used in metaphors, cases of metaphoric use of kill-verbs have been considered.

All causative verbs in Modern English denote the notion of causation, i.e. a relation between situations (events), but they perform it differently in different situations. In certain contexts they may acquire features that might change their connotations. Langacker (1987:278) posits, "linguistic convention cannot provide a fixed, unitary expression for every conceivable situation that a speaker might wish to describe." There might be instances containing one and the same verb, possessing one definition, but different connotations in each instance (Langacker 1982:306). For example, the verb to kill can be used in different contexts and express different meanings by remaining in the general scheme of its primary definition, i.e. to cause to die.
\end{abstract}

1. A young woman of 30 was killed in the car accident on Highway 66.

2. The rapist killed his victims to keep his identity secret.

Lexical causatives embed the meanings of cause and result. However, in Example (1) the meaning of result prevails over that of the cause. Example (2) clearly expresses both the cause and the result equally. Different contexts modify the additional information denoted by the verb (the factor of intention, physical energy, etc). In Example (1) the aspect of intentionality is non-existent; while in Example (2) it is existent. Moreover, the same general definition of to cause to die can be denoted by different verbs, like to murder, to massacre, to assassinate, etc.

3. They paid the criminal a fortune to assassinate the leader of the rebellion.

4. Kyle murdered without hesitation, he loved the sensation. 
A new approach to the classifications of kill-verbs (Khachatryan 2012) unites transitive forms of kill-verbs. The verbs included in the top category are to kill (cause the death of a person or other living thing) and to murder (the unlawful premeditated killing of one human being by another). These verbs denote the nuclear meaning to cause to die without any additional information on the instrument, motivation or manner. To cause to die is semantically embedded in all kill-verbs.

Considering the variety of features of English causative verbs, there can be many potential criteria for classifications. The accuracy of some of them can pose further debate on the topic. If one collective classification of kill-verbs has to be proposed, it must be based on the most important characteristic - one thing that both unites the whole class of causatives and divides them into subgroups. That one main criterion is their nuclear meaning to cause to die. Firstly, verbs must be categorized according to their relation to the nuclear meaning. Secondly, they must be subcategorized and compared with each other based on the additional features they denote parallel with the nuclear one. The verbs can be further cross-categorized and cross-compared, but this should be done outside of the main classification.

\section{To kill}

The definition of the verb to kill in Longman Dictionary of Contemporary English (LDOCE) is "to make a person or animal die". The verb to kill itself is considered to be a prototypical causative because of its flexibility, and the causee cannot be omitted, it must be explicitly expressed. The verb to kill usually bounds its cause and effect stronger, intensifying the spatial and temporal distance between the cause and the effect.

5. In the late 1970s and early 1980s, the Guatemalan army killed tens of thousands of civilian indigenous peasants during so-called 'counterinsurgency'operations.

(BNC 2007:CJR 389)

6. According to one account the signal for revolt was given when Geoffrey de Lusignan killed one of the Duke's closest advisers.

(BNC 2007:EFV 1521)

7. I stood there and promised them that I would stay alive until I had killed the monster.

(BNC 2007:H8G 737)

In Examples (8) and (9) the verb to kill can be substituted by other kill-verbs such as to stab, to shoot, to massacre, etc. The reason for this broad choice is the context. In Example (8), the Instrument is not specified because of the vagueness of the action. In Example (9), background knowledge is decisive in determining a choice of verbs as battles usually include various instruments of killing like guns, knives, bombs, etc.

8. If he was vulnerable he was mortal, and if we could wound him we could kill him.

(Doyle "Sherlock Holmes, the Valley of Fear")

9. And therefore, in recounting the numbers of those who have been 
killed in battle, I cannot but think you have said the thing, which is not. (Swift "Gulliver's Travels")

Lemmens (1998:107) finds its agentival flexibility as one of the main reasons. In fact, to kill allows the use of both the Agent and Force. Example (10) illustrates a case, in which there are many ways of dying in the wild nature. The idea is collective, uniting pirates and the natural causes, that is why to kill is used - it can express each one of them.

10. The boys on the island vary, of course, in numbers, according as they get killed and so on. (Barrie "The Adventures of Peter Pan")

11. Acid rain kills Welsh fish.

(BNC 2007:B7G 197)

12. An advantage of wind is that it at least partially kills sound.

(BNC 2007:BNY 1441)

Besides, to kill is widely used in both direct and metaphorical speech. And finally, together with corresponding arguments it can express the meanings of the rest of killverbs, while others kill-verbs cannot exceed the boundaries of their meaning essentials and substitute each. The predominance of to kill may be demonstrated in the following examples.

13. The man killed three women and was sentenced to five years of prison.

14. The man, who had killed the women, was sentenced to twenty years of prison.

Firstly, the verb to kill expresses an action, i.e. "to cause to die" but does not necessarily specify the means. In Example (14) the man could have shot, stabbed, drowned or beheaded the victims. Next, the immediate participation of the Agent or the Force is not specified; the man could have killed the women himself, could have given out an order or used an instrument. However, the man most probably performed the action intentionally, as no court will sentence a person to twenty years of prison for an accident. Therefore, the indicator of volition is also perceivable.

In Example (13), the phrase of "five years of prison" most probably may indicate an accidental killing. Provided Examples (13) and (14) are not dependent on a context, the verb to kill may be simply replaced by the verbs to murder, assassinate, behead, stab, etc. The verbs can be substituted almost by any other murder-verbs, thus acquiring a more fixed meaning, i.e. verbs which allow valency expansion at the deep-semantic level (Khachatryan 2008). However, this is possible only if verb arguments are not added. If an instrument is added as an argument to the verb ("The man killed three women with the same knife..." "), it could be substituted only with those murder-verbs that semantically embed the knife, for example, with the verb to stab.

15. Five people were killed at the State Capitol today. 
16. A terrorist group murdered five people at the State Capitol today and threatened to blow out the building.

Example (15) introduces the mere fact, not the details and embeds an Agent/Force, however, it is not expressed at the surface-syntactic level just yet. The people could have died of a disease or been murdered (as illustrated in Example 16). By leaving the Agent/Force, Instrument and Motivation out, the actual idea of killing is emphasized. The fact that people were killed at the State Capitol, one of the most important buildings of the USA, is more crucial at the moment, rather than details that would probably follow later.

\section{To murder}

The definition of the verb to murder is "to kill someone deliberately and illegally" (LDOCE). This verb possesses peculiarities that distinguish it from the verb to kill. Firstly, the Agent is semantically embedded in the meaning of this verb.

17. Someone has murdered my master.

(BNC 2007:GV7 590)

18. I'm sure the people who murdered your father are up to something.

(BNC 2007:BP7 2133)

19. Father Morrow, 58, from Braemar, Aberdeenshire, had made the application alleging that Dr James Howe murdered the 22-year-old Hillsborough disaster victim at the nearby Airedale General Hospital

(BNC 2007:CFB 1192)

The Agent of the act of murdering must be an entity either possessing animate or human-like attributes. The role of human-like Agents can be performed by companies, communities, governments, etc. (Lemmens 1998:107).

20. I remember one meeting six months after the CIA had murdered Allende.

(BNC 2007:CF4 604)

21. Loyalists have killed nine people and the IRA have murdered eight in counties Down, Tyrone and Derry.

(BNC 2007:HJ4 4689)

22. The gunsmith would have murdered him or had a heart attack.

(BNC 2007:AMU 2496)

An interesting deviation from this pattern is presented in Example (23). Different uses of these verbs, however, are limited to literature, when the author has more freedom with language to support his own style and ideas.

23. "Would you murder me?" he stammered. "There is no murder," I answered. "Who talks of murdering a mad dog? What mercy had you upon my poor darling, when you dragged her from her slaughtered father, and bore her away to your accursed and shameless harem." "It was not I who 
killed her father," he cried. (Doyle "Sherlock Holmes, A Study in Scarlet") Secondly, the verb to murder possesses peculiarities that distinguish it from the verb to kill, namely the action denoted by this verb is almost always intentional.

24. Ben murdered his brother for money and wealth.

In Example (24) Ben obviously had the intention of killing, and he might as well have planned the action. As it is observed in Example (25), the verb to murder is used to denote a killing caused by personal relationships, i.e. two brothers. The verb to kill would also be possible, but, for example, the verbs to assassinate, to massacre or to execute would be irrelevant to the context. In Example (26) the killing is regarded as a crime, because it mentions the punishment (execution). The verb to murder always relates to immediate causation. With no intermediate causers, to murder is never used in case of orders.

25. "God forgive you!" cried Madame Charpentier, throwing up her hands and sinking back in her chair. "You have murdered your brother."

(Doyle "Sherlock Holmes, A Study in Scarlet")

26. One day, a young gentleman, who was nephew to my nurse's governess, came and pressed them both to see an execution. It was of a man, who had murdered one of that gentleman's intimate acquaintances.

(Swift "Gulliver's Travel")

27. "The secretary, Mr. Joseph Stangerson," said Lestrade gravely, "was murdered at Halliday's Private Hotel about six o 'clock this morning."

(Doyle "Sherlock Holmes, A Study in Scarlet")

28. I would have you call things by their right names. You say I murdered Peter Carey, I say I killed Peter Carey... for I knew that it was him or me.

(Doyle "Sherlock Holmes: the Valley of Fear")

29. If the Holy Father was murdered, the implications are profound.

(Brown "Angels and Demons")

In Example (28) the speaker distinguishes between to murder and to kill, because he wants to emphasize that he did not kill the victim deliberately, did not want to commit crime and, moreover, did not have any reasons for it. The reason he killed him was selfdefense. Example (27) illustrates another peculiarity, the emphasis on the deliberateness. To murder is considered a crime, a deliberate killing. It can be noted that the sentence is very similar to a crime report, i.e. states the exact place and time. If the verb to kill was used, the information of the crime would be lost. In case of to assassinate the victim would have to be a celebrity, famous politician or social activist. Example (29) seems incorrect because it contains to murder, not to assassinate. Context plays a decisive role as it was earlier announced that the Holy Father has died of illness. The new death cause changes the situation, this is why to murder is used to denote deliberateness and crime.

It is worth mentioning that the Patient can be inanimate entities. 
30. "You have murdered a world," he accused her. (BNC 2007:CM4

\section{To assassinate}

This verb is very similar to the verb to murder in the indicators of intention and planning that are stronger than in the verbs to kill and to murder, which have a very common usage and can be used in any context regardless of its topic. The verb to assassinate, meaning "to kill an important person" (LDOCE), is an exception in this manner. To clarify, this verb is common in formal contexts and its denotational meaning plays an important role in the usage of the verb. In essence, the instigator of this action is necessarily an Agent, and the Patient of the action is always a political or social personae.

31. On my departure they assassinated the President. (BNC 2007:HRS 128)

32. On $2^{\text {nd }}$ June 1914, the Archduke Franz Ferdinand and his wife, were assassinated by a Bosnian Serb and that triggered a series of events that led to the outbreak of war on $4^{\text {th }}$, August 1914 - the war that became known as The Great War. (BNC 2007:ALY 613)

33. In 1909 Ito was assassinated at Harbin in Manchuria by a Korean nationalist.

(BNC 2007:EDP 29)

Lemmens (1998:108) also points out the motivational background. If the motivation behind to kill and to murder can be a personal reason, like hatred or jealousy, the activities of the victim usually stand as a motivation for the assassinator.

34. A prime minister who sought to push an unpopular agreement through was assassinated by a religious nationalist in March 1951.

35. The man who assassinated John Kennedy was killed before he could take the punishment.

36. $t$ would be an easy way for a young man to go down into history? Not so many British Ministers have been assassinated as to make it minor incident.

(Conrad:The Secret Agent)

Both Examples (35) and (36) allow substitution of the verb to kill with to murder. Although to kill and to murder are grammatically correct, their use in this situation would be a marker of language incompetency. It can also be observed that the assassination mostly includes intermediary and immediate causer. The process is carried out in two stages. First, a criminal is identified, order is given out and the killing is planned by the actual organizers, which are the intermediate causers. Only then the act of killing is brought about by the killer, the immediate causer.

It is worth mentioning that the Agent and the Patient can be inanimate entities.

37. Finally, the KGB assassinated a dozen members of our group as a warning to the others.

(BNC 2007: CDA 1702) 


\section{Progressive Archbishop Romero is assassinated by right-wing forces.}

(BNC 2007:HH3 4767)

39. Manavendra Sharma, the Assam Congress (I) general secretary, was assassinated by suspected ULFA guerrillas in Guwahati on February 22.

(BNC 2007:HL4 1374)

\section{To execute}

The verb to execute employs two meanings. The first meaning is "to do something that has been carefully planned" (LDOCE), whereas the second one has the general definition of killing "to kill someone, especially legally as a punishment” (LDOCE). As a member of murder verb category, the connotation of this verb incorporates both meanings: it surely denotes killing, but in an organized, official manner and it certainly possesses high level of intention and organization.

40. Oliver Plunkett was an Irish Jesuit executed for treason on July 1, 1681 and canonised five years ago. (BNC 2007:B1J 428)

41. He too was arrested and later convicted of treason and executed.

(BNC 2007:AN0 570)

42. He executed, imprisoned or dispossessed many of his own relatives to ensure the containment of their territorial ambitions and safeguard against any attempted seizure of the throne. $\quad$ (BNC 2007: EF2 550)

43. Chinese authorities have executed a bank accountant who embezzled more than $\$ 175,000$ in the country's first such case of computer fraud, the Xinhua Daily Telegraph newspaper reported yesterday...

(BNC 2007:CPK 343)

It is also worth mentioning that the criminal probably went through a number of trials or was omitted deliberately before s/he was sentenced to execution, i.e. the judge, the witnesses, and the lawyers, the executors can be considered the indirect instigators of the action.

44. Several of its leaders were executed and many others sentenced to life imprisonment.

(BNC 2007: HLG 2368)

45. Many of the Yugoslavs and White Russians handed over were executed without trial by the Titoists and Russians. (BNC 2007: A2A 608)

46. People assembled in the room to witness how the terrorist was executed.

47. Franquet's trial lasted two week; he confessed to the charges against him, and was executed.

(Madison: Joan of Arc)

There is no doubt that execution cannot be accidental. However, there is an interesting aspect to be considered, i.e. the aspect of agentivity. The immediate causer and instigator of this action is usually the government, courts and other legal bodies, the intermediate causer and the implementer is the executioner. 


\begin{abstract}
48. As a result Eck, the doctor and the engineer were found guilty, sentenced to death and executed by firing squad on Luneberg Heath.
\end{abstract}

(BNC 2007:CDS 604)

As a rule, the Agent of this particular action should be the intermediate causer. On the other hand, execution is an official procedure, and the executioner is usually the representative of the government, as if he does not preserve his own identity throughout the process, but acts as a medium. In this case the Agent of the action is the immediate causer, the government, comprised of different officials, some of which did not even participate in the given action. The act, as illustrated in Example 48, is carried out as a mere procedure, devoid of any emotions.

49. Not a few ruffians whom he caught red-handed in flagrant acts of cruelty were executed without mercy. (Fuller "Brave Men and Women")

An interesting deviation can be observed in Example (50), where to murder does not possess its traditional features. First, the verb is used only when the context refers to capital punishment. It is implemented by an executioner who receives an order from the authorities. It is obvious here, that although there was an order, it was not from any kind of official authority. Next, there was no trial before the act. Third, the verb to assassinate could be used as the victim was to be killed because of its status.

50. Shortly afterward, the Office of the Swiss Guard received that document, along with the threat that the Cardinals will be publicly executed, one per hour, starting at seven p.m. tonight, in Rome.

(Brown "Angels and Demons")

\title{
To massacre
}

The official definition of this verb is "to kill a lot of people or animals in a violent way, especially when they cannot defend themselves" (LDOCE). As it can be deduced from the definition, the Patient of this action is expressed by the plural form of nouns which semantically embeds a collective noun.

51. The Kurds have been and are being massacred, and are dying of neglect - our neglect - by the tens of thousands because they tried to escape that massacre, which we did nothing to prevent.

(BNC 2007:ABJ 320)

52. For the first time in European history the Jews were not only persecuted, they were massacred.

(BNC 2007:BMV 380)

53. Ever since 1099, when the first crusaders captured the Holy City and massacred the people who lived there, Jews and Muslims alike, the Christians had always treated Jerusalem as though it belonged to them alone.

(BNC 2007:EFV 1446) 
54. This event reminded many of the Bartholomew's Day ninety years previously when three thousand French Protestants were massacred in Paris.

(BNC 2007:ALK 499)

55. They massacred the Filipinos, regarding them as little better than dogs.

(BNC 2007:CAL 1795)

Furthermore, it may be stated that not only the Patient of the action, but also the Agent embeds a collective noun.

56. Then the Israelis entered west Beirut, their Lebanese militia colleagues massacred the Palestinians in Sabra and Chatila and European armies established themselves in Beirut.

(BNC 2007:ANU 985)

57. The Palestine Liberation Organization (PLO) is forced to leave Beirut and Palestinians in the refugee camps are eventually massacred by Lebanese Christian forces.

(BNC 2007:HH3 4793)

58. According to the report Kuomintang troops brought over from the mainland massacred between 18,000 and 28,000 people following what was deemed to be a Communist-inspired rebellion which began on Feb. 28, 1947.

(BNC 2007:HLG 859)

The verb to massacre is usually realized by a number of people, although the instigator can be one person. Consider the following examples:

59. The king massacred pagans for their faith in old gods.

60. The soldiers carried out the order the next day, and massacred pagans of the city.

In Example (59) the king is the instigator of the action. However, it is clear that the action includes an intermediate causer, i.e. soldiers. As the intermediate causer is not mentioned, the main emphasis falls on the king himself, stressing his responsibility for the crime and making him the Agent. Further on, in Example (60) the soldiers are considered to be the Agents of direct causation, because their participation in the killing is more emphasized than the person who gave out the order.

To summarize, it is undeniable that even though the verbs mentioned above express killing, their use is limited to specific contexts. The semantic properties that distinguish kill-verbs, namely verbs to kill, to murder, to assassinate, to execute, and to massacre can be accounted for their highly context-dependent nature. The relevant use of causative verbs also excludes any misunderstanding concerning the setting and agentivity of the action. The notion of causation is closely connected to language competency for it relates not only to the surface-syntactic structure, but also to the deep-semantic structure of the verb. Some causatives like to assassinate embed very specific meaning that limit their usage only to specific contexts. The use of to assassinate in a context describing the killing of common citizens is as unacceptable as reporting the death of an atheist by means of the verb to martyr. In case of the absence of a context, an appropriate way to perceive the connotation of the verb is through the Agent/Force and the Patient/Object, 
which might provide additional information. The semantic role of the Instrument is also a sufficient support to the representation of the situation in one sentence. It may be concluded that the analysis of the verb alone is not enough to reveal its exact meaning in the given sentences. Valency expansion must be taken into consideration, as many arguments can complete the meaning. Thorough study of causatives, especially those under lexical category, is necessary to comprehend the conditions of the action and the entity responsible for the consequences. Verbs like to kill, to murder, etc. can semantically reveal details about the Agent of the action, the number of the Agents, volition, motives, manner, and instrument used by the killer.

Based on the newly proposed classification that unites verbs with the nuclear meaning "to cause to die" and emphasizes their additional features at the same time, the suggested classification of semantic classes of lexical causative verbs cannot be considered exhaustive. As linguistic data suggest, Modern English employs structured classifications of causative verbs that are already being analyzed from the surface-syntactic and deepsemantic viewpoints. All verbs under this classification have been classified according to their meanings and additional features, like the embedded instrument, etc. However, a detailed meaning of kill-verbs will be a new ground for further investigations and research. All claims made in this article are subject to further empirical investigation because causatives constitute an undiscovered domain, which has the potential to reveal new findings about structures and usage in different languages.

\section{References:}

1. Khachatryan, R. (2012) On Some Aspects of Semantic Roles and Their Meanings in Modern English. Romance and Germanic Philology. Yerevan: Lingva.

2. Khachatryan, R. (2008) Semantic and Syntactic Valency of Causative Verbs. // Romance and Germanic Philology, Pedagogy and Teaching Methodology. Yerevan: Lingva.

3. Kemmer, S. \& Verhagen, A. (1994) The Grammar of Causatives and the Conceptual Structure of Events. // Cognitive Linguistics, 5(2).

4. Langacker, R.W. (1982) Space Grammar, Analysability, and the English Passive. // Language, 58.

5. Lemmens, M. (1998) Lexical Perspectives on Transitivity and Ergativity: Causative Constructions in English. Amsterdam and Philadelphia: John Benjamins.

\section{Sources of Data:}

1. Barrie, J. The Adventure of Peter Pan. <http://www.gutenberg.org/files/16/16-h/16h.htm>

2. Brown, D. Angels and Demons. <http://www.miracle-girl.com/angels\&demons.pdf $>$

3. Conrad, J. The Secret Agent. <http://www.gutenberg.org/files/974/974-h/974-h.htm>

4. Doyle, A.C. Sherlock Holmes: A Study in Scarlet.

$<$ http://www.gutenberg.org/files/244/244-h/244-h.htm> 
5. Doyle, A.C. Sherlock Holmes: the Valley of Fear.

$<$ http://www.gutenberg.org/files/3289/3289-h/3289-h.htm>

6. Fuller, O.E. Brave Men and Women. <http://www.gutenberg.org/files/13942/13942h/13942-h.htm>

7. Madison, L. Joan of Arc. <http://www.gutenberg.org/files/34474/34474-h/34474h.htm>

8. Swift, Jonathan. Gulliver's Travel. <http://www.gutenberg.org/files/829/829-h/829h.htm>

9. Longman Dictionary of Contemporary English. $<\mathrm{http}: / / \mathrm{www}$.ldoceonline.com $>$

10. Oxford English Dictionary. <http://oxforddictionaries.com>

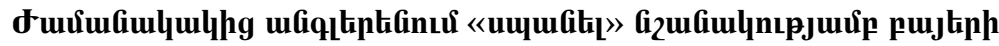

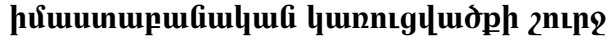

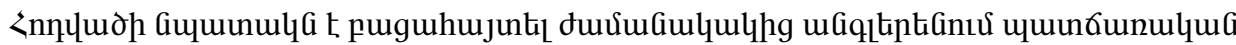

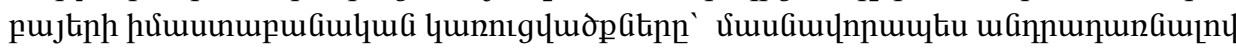

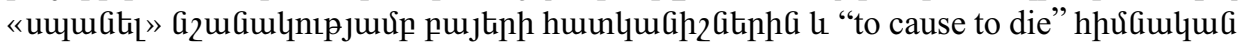

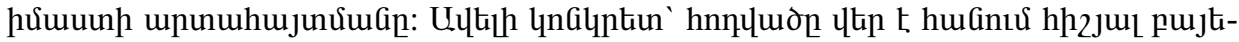

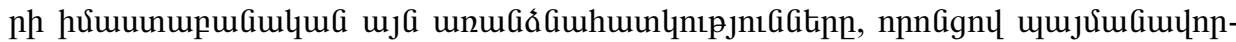

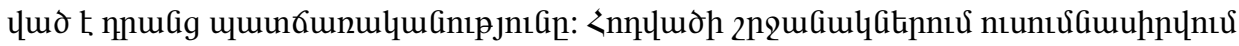

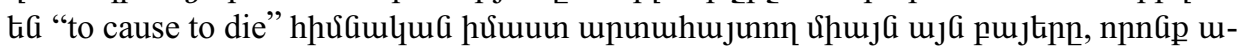

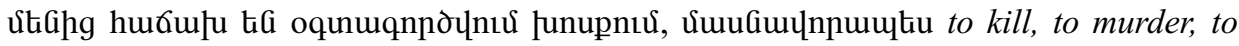

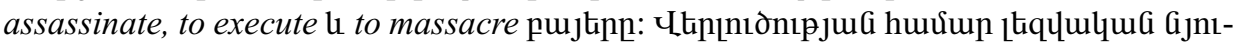

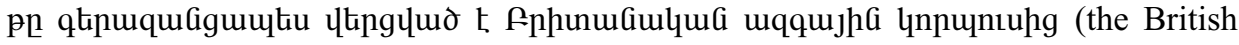
National Corpus). 